\title{
Blended Learning in Emergency Medicine: Implementing the E-Learning component
}

\author{
Fatimah Lateef ${ }^{1}$
}

\begin{abstract}
Blended learning (BL) refers to the combination of approaches to learning and teaching using a variety of delivery modes. It is playing an increasingly prominent role in medical education. Its strategy includes the combination of traditional face to face learning with e-learning, multimedia videos, online discussions and computer-based assessments. This paper discusses the steps undertaken in implementing an e-learning model through the utilization of a Blackboard system. The phases involved in the implementation include: 1) Training and Familiarisation: introductory learning session with hands-on trial and explanation of the system and its capabilities; 2) Deepening Understanding: formal training with real time trials and demonstration, as well as more complex problem handling; 3 ) Feedback: trainees and supervisors present and share experience of using the system and how to improve/ enhance it; 4) Assimilation and integration: final stage where knowledge and skills learnt are blended into clinical applications in daily practice. In combining e-learning with other forms of learning under the umbrella of $\mathrm{BL}$, there could be a notable shift from a teacher-oriented model to an active learner- centred one. The whole process emphasizes active learning, with collaboration between learners and supervisors, for the eventual delivery of best clinical care to patients.
\end{abstract}

Key words: blended learning, emergency medicine, blackboard, reflection, e-learning

\section{Introduction: Concept of Blended Learning}

The practice of medicine involves a lifelong learning process. The availability of various educational options and pedagogy to healthcare personnel is important to cater to the different needs. Today, there are new tools and platforms utilizing information technology (IT). The integration of these different modalities and pedagogical processes may serve the objective of providing the right learning, to the right healthcare personnel, in the right place, at the right time. There is no lack of choice and ingenuity, provided healthcare personnel have the courage and will, to embark on and try it out. Indeed, it is beginning to show clearly that technology can revolutionise the way we teach and learn (Davies et al., 2005).

\footnotetext{
${ }^{1}$ Senior Consultant/Director of Training and Education Dept of Emergency Medicine, Singapore General Hospital

Corresponding author:

Assoc Prof Fatimah Lateef

Dept of Emergency Medicine, Singapore General Hospital Block 1 Basement 1, Office $B$

Outram Road, Singapore 169608
}

E-mail: fatimah.abd.lateef@sgh.com.sg
Blended learning (BL) refers to the combination of approaches to teaching and learning, using a variety of delivery methods e.g. face to face learning, online collaborative learning. Learners and teachers can utilize the most effective components of each approach and derive the best bits from each resource. $B L$ should be a calculated combination to achieve the optimum training and learning solutions. In short, the right 'blend' can be crucial. BL can also address and accommodate different learning styles (Davies et al, 2005; Della Cort et al., 2005; Cleghorn et al., 2000).

In order to implement BL effectively, a frank and thorough review of the current or existing pedagogy must be done. This may include literature reviews, talking to others who have utilized BL, getting inputs from medical education experts as well as feedback from teachers and learners. This will highlight what is popular, what works, what is effective and what gets the message and understanding across to our learners. From here, a realistic model or framework, with the right 'blend' to address gaps can be derived. It becomes crucial to be aware of the support framework, IT support, cost and resources involved, 
security, as well as time commitment. The strategy, time-line for implementation, processes and objectives must also be defined clearly (Della Cort et al., 2005; Cleghorn et al., 2000).

In planning the programmes, both at undergraduate and postgraduate levels, it is essential to ensure they are pedagogically sound, operationally effective and provide quality knowledge and skills training. At the same time, they must be learner driven. The focus must also not be just on specific knowledge, but the application of knowledge to improve specific practice performance and clinical outcomes. The proportion of the physical and virtual elements must be presented in a balanced approach (Baker et al., 1998; Harden, 2002).

\section{Emergency Medicine and Blended Learning}

Physicians and healthcare personnel work in highly complex organizations and they need to understand how to evaluate and improve the systems they are involved in. Understanding how BL works and how it fits into individual physician's education and continuing professional development is important (Harden, 2002; Shah et al., 2008). According to the Accreditation Council for Graduate Medical Education (ACGME, 2005), physicians are required to investigate and evaluate their care of patients, appraise and assimilate scientific evidence, and to continuously improve patient care, based on constant self-evaluation and life-long learning. They are expected to develop skills to be able to:

- Identify strengths and limits in their knowledge and expertise;

- Set learning and improvement goals;

- Identify and perform appropriate learning activities;

- Analyze practice and implement changes with the goal of practice improvement;

- Incorporate formative evaluation feedback into daily practice;

- Use evidence-based practice and information technology to optimize learning;

- Participate in the education of patients, families, students, residents and other health professionals.

This is a comprehensive list that is all encompassing for a physician's education which will also have to be tailored to the appropriate specialty. In Canada, the CanMEDS Roles framework represents an equivalent initiative to improve patient care (Frank, 2005; Mickelson \& MacNeily, 2008). The framework defines the competencies needed for medical education and practice. The core competencies are organized theoretically around 7 key physicians' roles, i.e.:

1. medical expert

2. communicator

3. collaborator

4. manager

5. health advocate

6. scholar and

7. professional

The framework is relevant to multiple stakeholders: educators, teachers, trainees, practicing physicians, researchers etc. It also helps provide the 'big picture' in training curriculum and competency assessment in continuing education programmes (Frank, 2005; Mickelson, 2008).

$B L$, with the multitude of exposure and platforms available, will be able to provide and even value-add to the development and nurturing of these competencies over the period of training as well as within the lifespan of a physician.

The practice of Emergency Medicine is one dealing with the prompt stabilization, diagnosis and management of acute illnesses and injuries. Emergency physicians require a broad base of knowledge and skills, cutting across many different specialities and disciplines e.g. airway management (anaesthesia), fracture management (orthopaedics), and wound management (general surgery and plastics surgery) among others. Thus, the education and training of the emergency physician need to be well planned and comprehensive, with the right mix of didactic as well as practical knowledge and skills (Shah et al., 2008; Reznick \& Macrae, 2006; Haluck \& Krummel, 2000).

With such an array of information and skills to master, it is important to plan and structure a comprehensive implementation of the training. A certain degree of initial hand-holding and close supervision is essential. There will also be exposure to a variety of teaching tools and format e.g. case conference, mortality and morbidity rounds, journal clubs, interactive 
lectures, life support and simulation training (Shah et al., 2008; Reznick \& Macrae, 2006).

Bearing all these in mind, BL in Emergency Medicine must be carefully and thoroughly planned. It must be developed in response to local and organizational needs rather than just a generic approach adapted from others. Departmental readiness, technical resources, motivated faculty and learners, as well as a good network of communications and feedback are crucial elements to be considered. Faculty must be able to plan their own learning and also professional development. Initial concerns by teachers such as loss of control over students, poor performance and grades of their students/ learners must be addressed. This is also where faculty and learners need to get together to brainstorm the strengths and weaknesses of each type of learning environment - the traditional face to face contact learning versus the e-learning environment (Reznick \& Macrae, 2006; Haluck \&Krummel, 2000; Ruiz et al., 2006; Singh, 2003).

Engaging the faculty is crucial. We started off with introductory sessions, dialogues and feedback, initial hands-on demonstration and trials. Concerns and queries must be addressed and is best handled at each phase of implementation. It also helps to garner support from advocates or champions who can help get the 'buy-in' from others. We found the initial hand-holding period necessary and also implemented a 24-hour IT "helpdesk" service to handle queries.

\section{Incorporating the E-Learning component of $B L$}

Clinical teaching and learning in the Emergency Department is unique as there is always the consideration of wait times, high patient load, manpower constraints and managing the public's expectations. These factors may tend to limit education time when handling acute, emergent cases, but it is crucial to be able to seize the teaching moments in the midst of the provision of service.

E-learning utilises technology to deliver curricula and ultimately, to facilitate learning (Harden, 2002; Shah et al., 2008). In the healthcare industry, leveraging on technology does make sense for a variety of reasons- cost savings in the long term, flexibility, efficiency gains, ability to reach geographically dispersed learners and ability to address different learning styles (Harden, 2002; Shah et al., 2008; Ruiz et al., 2006).

The Blackboard is a management system which offers an interactive e-learning platform, accessible to both students/trainees and faculty/trainers/supervisors. Using the Blackboard system, e-learning is implemented to enhance the learning experiences of trainees. It represents yet another learning tool. It allows faculty and trainers to post materials, tests, surveys, questions, interactive lectures, video of practical skills and other course materials onto the system, which are then accessed by trainees and students. Blackboard training and assignments ensures a continuous 'dialogue' with the learners. In making a decision to use this modality, it is important to bear in mind that not everyone is comfortable with technology and some may not even have access to a computer. Thus, training and case materials on the Blackboard need to be planned and tailored to a range of learner capabilities.

Upon making the decision to implement this system, it is necessary to ensure participation and buy-in from all stakeholders, as all teaching materials will eventually be disseminated through the system. This also includes handing in of assignments electronically.

In implementation, the first step involves Training and Familiarisation. This is where hands-on trial sessions are held to introduce Blackboard e-learning. The teachers and trainers (in this case the supervisors are the faculty) too had to go through the same processes themselves. As the supervisors utilizing the Blackboard, they have to be comfortable with the system and know how to utilise it to put up assignments, course work and communicate with their learners.

The sessions for the medical officers and residents were done in controlled classroom setting. They were told about access, password usage, etiquette on the Blackboard, forms of interaction and communications as well as the do's and don'ts. Several classes were planned and those who required supplemental sessions, could arrange for them as well. During these classes, many of the senior doctors/ supervisors attended together with the medical officers and residents, in order to interact with their learners and have live trial sessions. In the initial phase, weekly training was conducted over a period of 2 
months. Initiatives were consolidated with a combination of 'bottoms-up' as well as 'driven from the top' approaches.

The next stage was to Deepen Understanding where the formal teaching sessions were conducted in real time using the Blackboard system and simulated examples. This is also when the users become familiar with the system, its capabilities and details as well as more complex case-handling, in a real day to day setting. The medical officers were told of the new uploads and assignments. The latter was important to assess learning and understanding. If they could access the system, do their assignments and homework and submit these accordingly, then it was likely they understood the use of the system and how to negotiate it. It also reflects their understanding. Some assessments were suitable to be done online whilst with others, 'real' supervisor- resident contact was required and these were planned by the pair accordingly. For example short answer questions, multiple choice assessments and project work submission were easily done electronically whilst clinical assessment of examination skills and techniques were better assessed face to face at the bedside.

This was also the period when the curricula was introduced to all. A summarized version is as seen in Table 1. The curriculum maps out in broad terms the knowledge domains, instructional methods and assessment strategies. These could be used in different combinations and permutations as deemed necessary by the teachers. They were given some flexibility in this context. The important thing is to ensure all knowledge domains are covered. Each teacher or team will plan the topics they are to cover and incorporate the appropriate degree of combination. This can be monitored through this new curricula.

Table 1: CURRICULUM: Blended Learning in Emergency Medicine

\begin{tabular}{|c|c|c|}
\hline $\begin{array}{c}\text { Instructional } \\
\text { Strategies }\end{array}$ & $\begin{array}{c}\text { Knowledge } \\
\text { Domains }\end{array}$ & Assessment \\
\hline \multirow{7}{*}{$\begin{array}{ll}\text { * } & \text { Lectures } \\
* & \text { Bedside Teaching } \\
* & \text { Problem-based learning } \\
* & \text { Scenario-based Teaching } \\
* & \text { Life Support Teaching } \\
* & \text { Simulation-based Training } \\
\text { (including online) } \\
\text { E - resources and } \\
\text { E-learning projects }\end{array}$} & Basic & \multirow{7}{*}{$\begin{array}{ll}* & \text { Projects } \\
* & \text { Presentations } \\
* & \text { MCQs } \\
* & \text { SAQs } \\
* & \text { Orals/Clinical } \\
& \text { OSCE }\end{array}$} \\
\hline & Sciences & \\
\hline & Clinical Knowledge & \\
\hline & Clinical Skills & \\
\hline & $\begin{array}{c}\text { Procedural } \\
\text { Skills }\end{array}$ & \\
\hline & Data Interpretation & \\
\hline & $\begin{array}{l}\text { Management and } \\
\text { Controversies }\end{array}$ & \\
\hline
\end{tabular}

* E-learning available and administered

After the programme had been implemented for 6 weeks, the formal Feedback phase commenced (Feedback was gathered throughout this process, by calls to the helpdesk staff and inputs from stakeholders i.e. the teachers and residents. Necessary rectifications and modifications were also made along the way as deemed needed). This is where both supervisors and medical officers/ residents gave inputs on the system, utilisation and partnership in training. This is important to assess if the system needs finetuning or changes, whether the medical officers and residents found the method of learning effective and also if the teachers could carry out the 'teaching' with ease. As the system must be user friendly, it was crucial to ensure the stakeholders involved were comfortable with it. New knowledge was shared with users and as the confidence level of users increased, they became capable of expanding the usage of the system, incorporating research proposals, reference elements and techniques to make knowledge sharing more dynamic.

With the new found enthusiasm, the final stage is the Assimilation and Integration of information and skills into practice. With strong buy-in, the whole department could use such a system at this point in the process. There are also further plans to expand training programmes and incorporate continuing education programmes. Utilization of IT in the processes involving teaching and learning is a dynamic one and will continue to evolve. Thus users must be prepared to face this so as not to feel helpless, and are able to make it an effective learning tool in their medical career. 
The e-learning programme also offers etutorials, e-resources (e.g. e-books and ejournals), step by step training and skills instructions with figures and animation, bulletin boards for comments and shared inputs, recorded lectures, simulations and animation. This is combined with the conventional learning done in the lecture room with interactive session, workshops, seminars, traditional journal clubs, journal reading, on the job training and job shadowing as well as rolemodelling (Stacey \& Gerbic, 2007; Vaughan, 2007; Bliuc et al., 2007; Garcia \& Newsome, 1996).

Following the implementation of the 4 staged, e-learning programme, it is important to be able to evaluate the effect and impact of both the e-learning component as well as the BL curriculum on the learners. Statistics such as frequency of access, proportion of assessment done online and face to face, how much comments and communications are online, rate of progression from stage to stage, personal habits change, as well as observations on the degree of self-reliance and motivation can be monitored. Other methods of evaluation include electronic logging in of procedures and cases, collation of marks for assessment techniques etc. As things were done electronically now, tracking was so much easier.

However, we have to be realistic that IT alone cannot improve the quality of healthcare delivery. It takes other elements such as a change in mind set, commitment, political will, inter-departmental collaboration and coordination as well as significant personnel buy-in and engagement.

\section{Discussion}

This paper discusses the steps involved in using technology to implement e-learning as part of BL. It also helps inculcate a new understanding and adaptation to the changing teaching and learning culture. From the more formal instruction format, the learning process is moving towards a more self-directed one with focus on experiential learning to enhance competence. During the process of implementation of the e-learning component, it was observed that there was progression from the initial nervousness and anxiety to that of competence and confidence when understanding was achieved. The latter was obvious as users came forth with suggestions to fine-tune and enhance the system, as well as new tools and curriculum to be covered on the Blackboard system. This is the result of the process of reflection by the users, where they have systematically gone through a conscious effort, reflecting on their practice of medicine. This exercise also allows the facilitation of the collaborative model of adult learning where learners and supervisors come to the same learning platform to teach and learn from each other.

With this model of $B L$, there is really no right or wrong combination but more of an acceptable proportion incorporating the various modalities and platforms. It will continue to evolve. Departments and institutions will have to monitor and assess their own appropriate combination.

As this is a way of presenting the curriculum on a new platform (as versus having an entirely new curriculum), we will continue to gradually fine-tune it based on feedback and inputs.

An evaluation of the programme will be carried out in the next few months after several cohorts of junior doctors are put through it. Each cohort is made up of about 30 junior doctors. The evaluation will be done on several fronts: electronic tracking, online questionnaire survey from users, comparison of grades, timely submissions etc. compared to the previous method.

In implementing $\mathrm{BL}$, each institution or department must tailor it to their needs rather than just take on a generic approach. It is not just about adding technology, but is a scholarly and transformative redesign process within the department, as well as mindset change. The proficiencies and domains to be covered must be clear. The over-arching guide in this case would be the ACGME and CanMEDS framework. Goals must be set to ensure the different roles are met. Sufficient exposure and practice must be provided to the residents and medical officers. Self-learning skills and motivation are also important as part of the professional development and continuing education.

In the professional development context (one of the requirements of both ACGME and CanMEDS), the blend of technologies with face to face interaction is a means by which a community of practice can be established. The latter represents a group of people who share the same concerns, a set of passion or problems on a certain topic and can deepen their knowledge and expertise in this area by 
ongoing interaction and shared learning (Wenger, et al., 2002).

Today's e-learning curriculum goes beyond the delivery of information to encourage indepth learning and this includes: communications, information and data handling, development of clinical skills, decision making and even ethics scenarios (Harden, 2002).

\section{Conclusion}

This paper shares an example of using the Blackboard e-learning system that emphasizes self-directed, active learning with elements of reflection and collaboration. It utilises the model to help residents and medical officers enhance their knowledge and skills and eventually, execute effective clinical care, when combined with more traditional learning in a BL model. In our training of emergency physicians, this has proven to be a positive step thus far, even as it is relatively new. The wide range of knowledge and skills covered under the Emergency Medicine curriculum, which crosses various disciplines, makes $B L$ a suited approach to reach out to learners with different learning preferences, learning rates and capabilities.

It appears to increase flexibility and personalization of learning, with a more robust and meaningful learning environment. BL will be the predominant model of the future with the new paradigm shift in learning, no longer restricted by four walls and face to face contact.

\section{References}

ACGME(2005) Advancing Education in Practicebased learning and Improvement [Online] Available at http;//www.acgme.org/outcomes/ implement/complete_PBLIBooklet.pdf.

Baker, G., Gelmon, S., Headrick L.A., Knapp, M., Norman, L., Quinn, D. \& Neuhauser, D. (1998) Collaborating for improvement in health professions education, Quality Management in Health Care, 6, 2, pp. 1-11.

Bliuc, A., Goodyear, P. \& Ellis, R. (200) Research focus and methodological choices in studies into student experiences of blended learning, Internet and Higher Education, 10, pp. 231-244.

Cleghorn, G. \&Baker, G. (2000) What faculty need to learn about improvement and how to teach it to others, Journal of Interprofessional Care, 14, pp. 147-159.
Davies, A., Ramsay, J., Lindfield, H. \& Couperthwaite, J. (2005) A blended learning approach: added value and lessons learnt from students' use of computer-based materials for neurological analysis, British Journal of Educational Technology, 36, 5, pp. 839-849.

Della Corte, F., LaMura, F. \& Petrino, R. (2005) Elearning as educational tool in emergency and disaster medicine training, Minerva Anaesthesiologica, 71, 5, pp.181-195.

Frank, J.R. (Ed). (2005). The CanMEDS 2005 physician competency framework. Better standards. Better physicians. Better care. Ottawa: The Royal College of Physicians and Surgeons of Canada.

Garcia, R. \& Newsome, R. (1996) Learning and change among emergency physicians, The Journal of continuing education in the health professions, 16, pp. 33-41.

Haluck, R.S. \& Krummel, T.M. (2000) Computers and virtual reality for surgical education in the $21^{\text {st }}$ century, Archives of Surgery, 135, pp.786792.

Harden, R.M. (2002) Myths and e-learning, Medical Teacher, 24, 5, pp. 469-472.

Mickelson, J.J. \& MacNeily, P.E. (2008) Translational education and tools for implementing the CanMEDS competencies in Canadian Urology residency training, Canadian Urological Association Journal, 2, pp. 395-404.

Reznick, R.K. \& Macrae, H. (2006) Teaching surgical skills- changes in the wind, New England Journal of Medicine, 255, pp. 26642669.

Ruiz, J.G., Mintzer, M.J. \& Leipzig, R.M. (2006) The impact of e-learning in medical education, Academic Medicine, 81, 3, pp. 207-212.

Shah, I.M., Walters, M.R. \& McKillop, J.H. (2008) Acute medicine teaching in an undergraduate medical curriculum: a blended learning approach, Emergency Medicine Journal, 25, pp. 354-357.

Singh, H. (2003) Building effective blended learning programmes, Educational Technology, 43, 6, pp. 51-54.

Stacey, E. \& Gerbic, P. (2007) Teaching for blended learning: research perspectives from on campus and distance students, Educational and Information Technologies, 12, 3, pp. 165-174.

Vaughan, N. (2007) Perspectives on blended learning in higher education, International Journal on ELearning, 6, 1, pp. 81-94.

Wenger, E., McDermott, K.\& Synder, W.M. (2002)Cultivating a community of practice, Boston: Harvard University Press. 